This is the peer reviewed version of the following article:

Sociolinguistic Perspectives on Migration Control: Language Policy, Identity and Belonging

First published: 13 Nov 2020

which has been published in final form at https://onlinelibrary.wiley.com/doi/10.1111/josl.12444

This article may be used for non-commercial purposes in accordance with Wiley Terms and Conditions for Self-Archiving." 


\section{Sociolinguistic Perspectives on Migration Control: Language Policy, Identity and Belonging, Markus Rheindorf, Ruth Wodak (Eds.) Language, Mobility and Institutions. Bristol, Blue Ridge Summit: Multilingual Matters. 2020. viii + 172 pp. Hb (9781788924672) £89.95, Pb (9781788924665) £24.95, Ebook (9781788924689) £15.00.}

Sociolinguists have great potential to make a positive impact in the world, and the area of migration control is no exception in this regard (Clyne, 2003). However, editing a book that gathers sociolinguistic perspectives on migration is not a straightforward task:

sociolinguistics as a field and migration as an area of study each represent a plethora of possible approaches. This means that a seven-chapter edited collection will never be able to represent all the possible intersections. Yet, this book successfully captures the diversity of scholarship in this field in multiple ways. The chapters offer a diversity of methodologies, of perspectives, of types and stages of migration, of languages, and - to some extent - of geographic focus.

In the introductory Chapter 1, Markus Rheindorf and Ruth Wodak tackle the challenging task of bringing together this diversity into a cohesive conceptual framework. Their emphasis on migration control helps to delineate the book's focus, and underlines the connection that each of the studies has with law and/or politics. Importantly, the editors acknowledge a limitation of the book: while each chapter represents research relating to a different country, and spanning a variety of languages, the collection is Western-centric, covering case studies from the US, the EU and Israel. Similarly, Chapter 1 most heavily emphasises the European context, reflecting its authors' expertise. Despite these limitations, Rheindorf and Wodak succeed in presenting a theorization of discourses of migration control that helps start the conversation that develops through the remainder of the book's chapters, exploring the multiple ways language intersects with migration and migrant-related policy. 
In Chapter 2, Kristof Savski provides a comprehensive historical overview of evolving Slovene language policy vis-à-vis people who have migrated from other states of the former Yugoslavia. He maps the diminishing status afforded to "Serbo-Croat", his chosen umbrella term for "all standard and non-standard historical and present-day varieties of Serbian, Croatian, Bosnian and Montenegrin" (p. 37). Savski demonstrates how the changing status of Serbo-Croat and its speakers is closely determined by socio- and geopolitical factors. In itself, this chapter employs a range of sociolinguistic approaches. It critically examines language policy development and change, beginning with a detailed historical, socio-political contextualization, and finishing with a critical discourse analysis of recent language policy debates. However, it also involves linguistic comparative examinations of Slovene and Serbo-Croat, descriptions of language acquisition and transfer, and explores the development of a Slovene/Serbo-Croat sociolect, situated within second-generation identity making.

Chapter 3 identifies similar tensions between language as a means to control and exclude, and migrants' agency and creativity in addressing such discrimination through positive identity construction. Tony Capstick takes us to the UK, where he shares with the reader a discourse-ethnographic study of Pakistani migrants" "migration literacies". This multi-site study provides a rich examination of the language practices of a migrant family as they confront discrimination in a range of settings. The chapter presents three illuminating ethnographic vignettes focused on Usman, a recent migrant from Mirpur, Pakistan.

Capstick's critical discourse analysis of these vignettes demonstrates how Usman draws on a range of literacies to subvert and resist situations where he risks social exclusion. The first involves Usman's experience in his workplace, being targeted as a recent migrant working alongside second-generation British Mirpuris, and explores the discursive strategies he uses to construct a positive identity vis-à-vis his colleagues and thereby resist discrimination. The 
second vignette focuses on the visa application process, and identifies the important role that professional migration advice can play in appropriating suitable bureaucratic literacies. The third explores Usman's multilingual vernacular literacy in constructing an identity as a dedicated father and husband among his in-laws, family and community on Facebook, as a means of resisting stigmatizing discourse about migrants being involved in "sham" marriages.

Resistance through discourse is also foundational in Anna De Fina's study, presented in Chapter 4. Both Capstick and De Fina address a heavy imbalance in migration-andlanguage research which rarely centres the perspectives and voices of migrants themselves. De Fina explores the storytelling practices of Dreamers, people brought to the US as children by their undocumented parents. She uses a combination of quantitative and qualitative approaches to examine 13 mostly auto-biographical narratives. She explores how they contribute to the broader Dreamers Movement, aimed at improving Dreamers' legal rights in the US, making storytelling a valuable form of self-advocacy. Valuably, De Fina is able to compare the discourses arising in the current study with those she identified in an earlier examination of Dreamer texts, and is therefore able to map the way narratives have adapted in response to changing legal and political conditions.

Chapter 5 once again centres migrants' narratives, albeit in a different context: Jo Angouri, Marina Paraskevaidi and Federico Zannoni draw on a corpus of interviews with individuals who have migrated from Greece, or migrated to Italy, to explore how they make sense of their migration experiences. They identify a set of themes emerging from the interviews, based on which the participants construct belonging and position themselves. They find that these constructions mobilize a set of binaries, us and them, here and there, and now and then, and 'in-between-ness', but the variety of perspectives and narratives simultaneously demonstrates the diversity and complexity of migration experiences. While 
this chapter does not have a heavy focus on law or policy, the authors still draw connections with these. The participants' discourses about migration, identity and belonging are inextricably linked with host country discourses, and their adoption of counter-discourses is a powerful example of individual agency. Further, the study itself, by showcasing the diversity, complexity and fluidity of individual migrants' experiences and perspectives, helps counter negative and homogenizing dominant discourses. In this way the authors support their own call for applied and sociolinguistics to contribute to an "alternative narrative which is overdue and urgently needed" (p. 110).

Also answering this call, Rheindorf and Wodak adopt another approach in Chapter 6, involving a critical analysis of media discourse about migrants. Focusing on the Austrian context, the authors examine a large corpus of print media to identify dominant discourses about migrants, asylum seekers and refugees, mapped against key political events. They find, similar to De Fina's study, that changes in discourse correlate with these events. They demonstrate how these discourses are used to legitimate (generally increasingly restrictive) migration law and policy changes. The chapter's findings make a valuable contribution to a growing body of international scholarship on media discourse about refugees and migrants. However, what is even more striking in this chapter is its meticulous implementation of a broad range of established quantitative and qualitative critical discourse methodologies. These include a Discourse-Historical approach, and a multi-level analysis of a large corpus. They started with multiple quantitative analyses, including identifying nomination patterns, conducting a semantic field analysis, investigating intercollocation, and mapped key collocates over time (eg Baker et al. 2008). These informed a downsampling of the corpus for qualitative analysis. Texts in the smaller sample were then analysed for legitimation strategies (van Leeuwen 2007; Wodak \& Van Leeuwen 1999). The chapter thus provides a model for junior researchers, or others wishing to engage with Critical Discourse Studies in 
their scholarship, and, alongside the other chapters, showcases the methodological diversity of this field.

Indeed, perhaps the most obvious thread throughout this book - although this is not evident from its title - is the collection's focus on discourse. Each of the chapters incorporates different, generally critical, examinations of discourses on migration control. Chapter 7 is no exception in this regard, offering yet another approach, with a case study of public discussions about Thai migrant workers in the agricultural industry in the Arava region of Israel. Situated within a larger project, Iair G Or and Elana Shohamy examine ten online news and media items related to this topic, as well as the reader comments accompanying them. The result is a rich and engaging analysis of the clashing perspectives and interests of the state, the farmers and other citizens, drawing on themes of national identity, security, economics and rights. While this is primarily a case study of language about migration (and related laws and practices), language in migration is also addressed. The authors acknowledge how unequal sociolinguistic resources determine who contributes to the debates they explore. Particularly, unlike many of the other chapters in this collection, the perspectives of the Thai migrant workers themselves appear infrequently in the data. Their temporary visa status, limited Hebrew and social isolation undoubtedly limit their participation in debates concerning them and their experiences.

Rheindorf and Wodak have succeeded in assembling a diverse yet cohesive collection of sociolinguistic studies on migration control, likely to interest a broad readership. This includes those interested in the language-migration research intersections, or more generally in the interplay between language and policy making (both including but also more broadly than just language policy). Incorporating data in several different languages, they explore multi-generational migrant groups, those without legal status, permanent economic migrants, refugees and asylum seekers, and temporary migrant workers. This means that various parts 
of the book are likely to appeal to a variety of readers interested in migration-related research. The range of methodological and conceptual approaches included offers a valuable showcase for emerging sociolinguist researchers, beyond those interested specifically in migration.

In line with the editors' aims, this collection contributes to sociolinguistics a better understanding of the multiple ways in which language and migration control intersect. Moreover, both the methodologies and findings of the compiled studies demonstrate some of the many ways in which sociolinguists can challenge harmful anti-migrant discourses in their scholarship (p. 10). An important further step, which is not dealt with in this collection, is to critically reflect on how sociolinguists and other scholars can transform their work to reach broader audiences beyond academia (see e.g. Kraft \& Flubacher 2020). This is a crucial undertaking to ensure that scholarship lends support to migrant-led advocacy and practices of resistance, like those explored in this book.

Reviewed by Dr Laura Smith-Khan, Chancellor's Postdoctoral Research Fellow, University of Technology Sydney.

\section{References}

Baker, P., Gabrielatos, C., KhosravinNik, M., Krzyżanowski, M., McEnery, T. and Wodak, R. (2008). A useful methodological synergy? Combining critical discourse analysis and corpus linguistics to examine discourse of refugees and asylum seekers in the UK press. Discourse \& Society, 19(3), 273-305. doi: 10.1177/0957926508088962

Clyne, M. (2003). When the discourse of hatred becomes respectable - does the linguist have a responsibility? Australian Review of Applied Linguistics, 26(1), 1-5. doi: 10.1075/aral.26.1.01cly

Kraft, K. and Flubacher, M. (2020). The promise of language: Betwixt empowerment and the reproduction of inequality. International Journal of the Sociology of Language, (264), 1-23. doi: 10.1515/ijsl-2020-2091.

van Leeuwen, T. (2007). Legitimation in discourse and communication. Discourse \& Communication 1(1), 91-112. doi: 10.1177/1750481307071986.

van Leeuwen, T. and Wodak, R. (1999) Legitimizing immigration control: A discoursehistorical analysis. Discourse Studies 1(1), 83-118. doi: 10.1177/1461445699001001005 